Voix et Images

voixetimages

\title{
Yves Thériault et l'Institution littéraire québécoise
}

\section{Benoît Melançon}

Volume 10, numéro 1, automne 1984

Littérature canadienne-anglaise

URI : https://id.erudit.org/iderudit/200469ar

DOI : https://doi.org/10.7202/200469ar

Aller au sommaire du numéro

Éditeur(s)

Université du Québec à Montréal

ISSN

0318-9201 (imprimé)

1705-933X (numérique)

Découvrir la revue

Citer cet article

Melançon, B. (1984). Yves Thériault et l'Institution littéraire québécoise. Voix et Images, 10(1), 174-175. https://doi.org/10.7202/200469ar d'utilisation que vous pouvez consulter en ligne.

https://apropos.erudit.org/fr/usagers/politique-dutilisation/ 


\title{
Yves Thériault et l'Institution littéraire québécoise
}

\author{
par Benoît Melançon, Université de Montréal
}

À la suite de la parution de l'Institution de la littérature (1978) de Jacques Dubois et des travaux du sociologue Pierre Bourdieu, il est devenu à la mode d'étudier la littérature en tant qu'ensemble d'appareils institutionnels. C'est dans la foulée des travaux de Dubois et de Bourdieu, mais aussi de l'esthétique de la réception de Hans Robert Jauss, que Hélène Lafrance a scruté les rapports entre Yves Thériault et l'Institution littéraire québécoisel de 1944 à 1964. Présentées comme mémoire de maîtrise à l'Université de Sherbrooke en 1983, ses recherches lui ont valu le Prix Edmond-de-Nevers de l'Institut québécois de recherche sur la culture.

L'hypothèse de Lafrance est que Thériault est souvent mal perçu par la critique «à cause de certains côtés populaires de son ouvre» et parce qu'il se situe, dans le champ littéraire, «à mi-chemin de la légitimité et de la nonlégitimité». Participant tantôt de la sphère de production restreinte de l'appareil institutionnel, tantôt de la sphère de grande production, l'œuvre de Thériault aurait été tenue dans une relative «marginalité » par une critique incapable d'accepter à la fois productions populaires et littérature "consacrée». Thériault, par choix esthétique et par manque de capital social, scolaire et culturel, aurait difficilement traversé les «étapes de la consécration », sauf dans le cas de Contes pour un homme seul et de la «trilogie des minorités " (Aaron, Agaguk, Ashini).

Dans cette optique, les pages que consacre Lafrance à la carrière de Thériault et à la réception critique de ses textes sont convaincantes, tant par la qualité de l'information que par l'articulation que donne l'auteure à cette information. On aurait toutefois souhaité davantage de distance entre les propos de Lafrance et ceux de Thériault, que le découpage chronologique soit moins rigide et que certaines affirmations soient moins tranchées: existe-t-il vraiment une "prédilection de l'institution universitaire pour les romanciers psychologiques»? Qu'est-ce qui permet de croire que «l'institution littéraire a plutôt tendance à marquer l'heure avec quelques décennies de retard $»$ ?

Là où l'étude est plus discutable, c'est lorsque l'auteure tente de faire le lien entre institution et textes. Plus largement qu'au travail de Lafrance, ce reproche pourrait être adressé à la quasi-totalité des publications sur l'institution littéraire: si la recherche institutionnelle réussit à renouveler, entre

1. Hélène Lafrance, Yves Thériault et I'Institution littéraire québécoise, Québec, Institut québécois de recherche sur la culture, coll. "Edmond-de-Nevers" 3, 1984, 174 p. 
autres, les approches biographiques et sociologiques du fait littéraire, elle parvient rarement à montrer ce que fait, et où elle le fait, l'institution dans les textes. L'analyse institutionnelle n'est pas qu'une analyse du littéraire en tant que système : elle est aussi une analyse des marques du système sur et dans les textes.

Lorsque Lafrance étudie les «types de production» de Thériault (littérature consacrée, de jeunesse, populaire, radiophonique), elle propose des analyses thématiques et idéologiques; de même, lorsqu'elle compare les versions romanesque et radiophonique d'Aaron et d'Ashini, elle reste dans l'analyse de contenu. On voit difficilement comment l'institution est effectivement à l'œuvre dans les textes du conteur, sinon par l'adéquation des messages à divers publics, ce qui n'est pas en soi de l'analyse institutionnelle, ou par la transgression des codes, ce qui aurait demandé de plus importants développements que ceux que lui consacre Lafrance. On aurait aimé que l'auteure utilise, par exemple, les importants travaux d'André Belleau sur la notion de codes littéraires : le Romancier fictif (PUQ, 1980) et les textes de Liberté auraient trouvé ici un beau champ d'application.

Malgré ces réserves, il faut saluer la publication d'Yves Thériault et l'institution littéraire québécoise. Si l'on excepte quelques recherches aux universités Laval et de Sherbrooke, un numéro de Liberté (134, mars-avril 1984), un ouvrage collectif (à paraître) sur les institutions littéraires belge et québécoise, ainsi que des articles épars, la recherche institutionnelle au Québec en est encore à ses premiers balbutiements. L'ouvrage de Lafrance n'en prend que plus de valeur: sa présentation de l'institution littéraire de 1944 à 1964 a au moins autant de mérite que sa défense de notre premier écrivain professionnel, et des genres paralittéraires. 